Pesq. Vet. Bras. 1322-1326, novembro 2017

DOI: $10.1590 / \mathrm{S} 0100-736 \mathrm{X} 2017001100020$

\title{
Avaliação de peptídeo natriurético em cães doentes renais crônicos ${ }^{1}$
}

\author{
Felipe A.C.S. $\mathrm{Cruz}^{2}$, Mariana M. Torres ${ }^{2}$, Daiane Poletto ${ }^{3}$, Adriane J. Mendonça ${ }^{4}$, Luciana \\ D. Guimaraes ${ }^{4}$, Arleana B.P.F. Almeida ${ }^{4}$, Felipe G. Silva ${ }^{4}$ e Valéria R.F. Sousa ${ }^{4 *}$
}

\begin{abstract}
Cruz F.A.C.S., Torres M.M., Poletto D., Mendonça A.J., Guimaraes L.D., Almeida A.B.P.F., Silva F.G. \& Sousa V.R.F. 2017. [Natriuretic peptide assessment in dogs with chronic kidney disease.] Avaliação de peptídeo natriurético em cães doentes renais crônicos. Pesquisa Veterinária Brasileira 37(11):1322-1326. Programa de Pós-Graduação em Ciências Veterinárias, Universidade Federal do Mato Grosso, Av. Fernando Corrêa da Costa 2367, Bairro Boa Esperança, Cuiabá, MT 78060-900, Brazil. E-mail: valeriaregia27@gmail.com

In chronic kidney disease (CKD) hypertension is one of the most common complications that may be associated with the release of natriuretic peptides and ventricular hypertrophy in humans. In dogs the natriuretic peptides are studied as cardiac biomarkers, but still unaware their function in dogs with CKD. Thus, this study aimed to relate the serum natriuretic peptide B with blood pressure findings, electrocardiographic, electrolyte, blood and serum and urinary biochemistry in dogs in different stages of CKD. Significant differences were found in urinary protein to creatinine ratio (UPC, $p=0.006$ ), anemia, serum creatinine and urea $(\mathrm{p}<0.001)$ in the group of patients with renal disease compared with the healthy group. Despite the variation in blood pressure, amplitude and QRS interval and phosphorus are not significant, a tendency for alterations of these values was observed with the advance of the disease. There was no correlation between BNP and CKD.
\end{abstract}

INDEX TERMS: Chronic kidney disease, dogs, natriuretic peptide, arterial hypertension.

RESUMO.- Na doença renal crônica (DRC), a hipertensão arterial é uma das complicações mais comuns, que pode estar associada a liberação dos peptídeos natriuréticos e a hipertrofia ventricular no homem. Em cães os peptídeos natriuréticos são estudados como biomarcadores cardíacos, mas ainda se desconhece sua função em cães com DRC. Desta forma, este estudo teve como objetivo relacionar a concentração sérica de peptídeo natriurético B aos achados de pressão arterial, eletrocardiográficos, eletrolíticos, hematológicos e bioquímicos séricos e urinários em cães nos distintos estágios da DRC. Foram constatadas diferenças significativas na

\footnotetext{
${ }^{1}$ Recebido em 15 de fevereiro de 2016.

Aceito para publicação em 14 de fevereiro de 2017.

${ }^{2}$ Programa de Pós-Graduação em Ciências Veterinárias, Universidade Federal de Mato Grosso (UFMT), Av. Fernando Corrêa da Costa 2367, Bairro Boa Esperança, Cuiabá, MT 78060-900, Brasil.

${ }^{3}$ Programa de Residência Uniprofissional em Medicina Veterinária, UFMT, Av. Fernando Corrêa da Costa 2367, Bairro Boa Esperança, Cuiabá, MT 78060-900, Brasil.

${ }^{4}$ Departamento de Clínica Médica Veterinária, Faculdade de Agronomia, Medicina Veterinária e Zootecnia (FAMEVZ), UFMT, Av. Fernando Corrêa da Costa 2367, Bairro Boa Esperança, Cuiabá, MT 78060-900, Brasil. *Autor para correspondência: valeriaregia27@gmail.com
}

relação de proteína creatinina urinária (UPC, $\mathrm{p}=0,006$ ), anemia, creatinina e uréia sérica $(\mathrm{p}<0,001)$ nos grupos de doentes renais comparado com saudáveis. Apesar das variações de pressão arterial, amplitude e intervalo QRS e fósforo não serem significativas, foi observada tendência de alteração desses valores com o avanço da doença. Não foi observado correlação entre BNP (peptídeo natriurético cerebral) e DRC.

TERMOS DE INDEXAÇÃO: Doença renal crônica, cães, peptídeo natriurético, hipertensão arterial.

\section{INTRODUÇÃO}

A Doença Renal Crônica (DRC) é caracterizada por lesões irreversíveis nos rins de caráter progressivo, ocorrendo de meses a anos, frequente em cães idosos, porém, pode ocorrer em todas as idades (McGrotty 2008, Polzin et al. 2011, Bartges 2012). Com a perda de néfrons ocorre a diminuição da taxa de filtração glomerular (TFG) resultando em azotemia pelo aumento da concentração de compostos nitrogenados no sangue. Adicionalmente, ocorre a excreção de substâncias que deveriam ser reabsorvidas pelos túbulos como as proteínas, levando à proteinúria, um biomarcador de lesão renal (Polzin et al. 2011, Bartges, 2012). 
A avaliação laboratorial, juntamente com a anamnese e o exame físico, possibilita a detecção das alterações e complicações associadas à DRC, dentre elas, a hipertensão arterial que é uma das complicações mais comuns, embora sua patogenia ainda não seja totalmente conhecida, esta é gerada de forma multifatorial. Os órgãos mais comprometidos pela hipertensão são os rins, os olhos, o cérebro e o sistema cardiovascular (Polzin et al. 2011, Bartges 2012, Courand \& Lantelme 2014).

A hipertensão arterial, assim como a isquemia e hipóxia do miocárdio podem levar ao aumento da liberação dos peptídeos natriuréticos pelos cardiomiócitos. Entre os peptídeos estão o peptídeo natriurético atrial (ANP) e peptídeo natriurético cerebral (BNP). A função dos peptídeos natriuréticos pode estar associada à regulação da pressão sanguínea em pacientes humanos, e são cada vez mais utilizados como marcadores para o diagnóstico e prognóstico de doença cardíaca (Connolly et al. 2008, Cavalcante et al. 2013).

Em gatos hipertensos com DRC moderada se observou elevação da concentração dos peptídeos natriuréticos ao compará-los com gatos normotensos com DRC moderada, liberados pelos miócitos ventriculares induzindo a hipertrofia ventricular, que pode ocorrer antes mesmo do aparecimento da alteração cardíaca propriamente dita (Lalor et. al. 2009). Caso seja observada esta mesma alteração em cães, essa ferramenta se torna importante para um diagnóstico precoce de alterações cardiovasculares em doentes renais crônicos. Diante do exposto, este estudo teve como objetivo relacionar a concentração sérica de BNP aos achados de pressão arterial, eletrocardiográficos, eletrolíticos, hematológicos e bioquímicos séricos e urinários em cães nos distintos estágios da DRC.

\section{MATERIAL E MÉTODOS}

Este trabalho foi aprovado junto ao Comitê de Ética no Uso de Animais da Universidade Federal do Mato Grosso (CEUA-UFMT) sob o número 23108.093961/2015-41.

No período de abril de 2014 a maio de 2015, cães de diferentes raças, sexo e faixa etária foram atendidos no Hospital Veterinário da Universidade Federal de Mato Grosso (UFMT), campus Cuiabá, com DRC caracterizada pela concentração sérica elevada de creatinina $(>1,5 \mathrm{mg} / \mathrm{dl})$ e/ou densidade urinária inferior a 1.018. De acordo com os critérios da Sociedade Internacional de Interesse Renal (IRIS), os cães foram divididos em quatro grupos: I (creatinina até $1.4 \mathrm{mg} / \mathrm{dL})$, II (1.5 a $2.0 \mathrm{mg} / \mathrm{dL})$, III $(2.1-4.9 \mathrm{mg} / \mathrm{dL})$ e IV (maior que $5 \mathrm{mg} / \mathrm{dL}$ ). Adicionalmente, um grupo controle com cães sem alterações clínicas foi formado para fins de comparação das variáveis analisadas. Os cães em terapia anti-hipertensiva e/ ou com histórico de cardiopatia foram excluídos do estudo.

Os cães foram examinados clinicamente e amostras de sangue foram coletadas da veia cefálica ou jugular externa, para hemograma, bioquímica, eletrólitos e dosagem do BNP, respectivamente. Amostras de urina foram coletadas por cistocentese ou sondagem para urinálise e avaliação da relação proteína creatinina urinária.

A mensuração da pressão arterial foi realizada com o auxílio do aparelho oscilométrico PetMap® (petMAP classic Blood Pressure Measurement Device), em triplicata, sendo realizada uma média dos três valores de pressão sistólica, diastólica e média, considerando os parâmetros de normalidade da pressão arterial média de acordo com Meurs et al. (2000) de 136, 101 e $81 \mathrm{mmHg}$ (sístolica, média e diástolica).
A metodologia para avaliação eletrocardiográfica foi de acordo com Essner et al. (2015) com avaliação de freqüência cardíaca, alterações de onda P, complexo QRS e onda T, utilizando o aparelho ECG PC- TEB ${ }^{\circledR}$. Para uma melhor avaliação dos achados eletrocardiográficos, as ondas foram avaliadas separadamente em Onda P, Intervalo PR, Intervalo QRS, Intervalo QT, Amplitude QRS e Amplitude T.

O hemograma completo foi realizado em Analisador Hematológico Automático Poch-100 iv Diff (Roche ${ }^{\circledR}$ ), e a bioquímica sérica no aparelho CELM SB-190 ${ }^{\circledR}$. Nas duas análises foram considerados valores de referência de Jain (1993) e Kaneko et al. (1997).

Os eletrólitos, bioquímica sérica e UPC foram mensurados com kits comerciais seguindo as recomendações do fabricante; cloro e potássio foram analisados pela técnica de espectrofotometria de chama; cálcio e fósforo pela técnica colorimétrica enzimática, assim como a concentração de proteína e creatinina urinária para cálculo da UPC (Kit Gold Analisa ${ }^{\circledR}$ ).

A urinálise foi realizada com a primeira urina do dia segundo metodologia de Garcia-Navarro (1996), sendo o exame químico avaliado por fitas reagentes comerciais para urinálise e a densidade urinária por refratometria.

A concentração de BNP foi mensurada com kit comercialmente disponível, o Ensaio NT-proBNP canino $\left(\right.$ Biomedical $^{\circledR}$ ) seguindo orientação do fabricante (Moesgaard et al. 2011).

Para análise estatística foi utilizado o programa SAS (Studios University Edition) para fazer o teste qui-quadrado seguido do Tukey para as variáveis normais e normais transformadas, e o teste Kruskal-Wallis seguido de Dunn nas variáveis que não seguiram normalidade. Foi testado também o efeito linear e quadrático em função da creatinina e do BNP para observar suas interferências nas variáveis analisadas. Foram considerados valores menores que 0,05 significativos.

\section{RESULTADOS}

Durante o período de estudo foram coletadas amostras de 52 cães, sendo 14 sem alterações clínicas que compuseram o grupo controle, 38 com DRC, sendo: estágio I (5), estágio II (9), estágio III (10) e estágio IV (14). No presente estudo observou-se diferença significativa dos achados de ureia e creatinina entre o grupo controle e os estágios 2, 3 e 4 da doença $(\mathrm{p}<0,05)$.

No Quadro 1 se encontram as variáveis analisadas seguido da média, desvio padrão, variância com ou sem normalidade.

Em relação ao sexo dos cães com DRC, 42,1\% (16) foram machos e 57,9\% (22) fêmeas. Enquanto de acordo com a faixa etária ficaram distribuídos em $<1$ ano (1), 1 a 6 anos (8), >7 anos (26) e não informado (3).

A maioria dos cães avaliados não tinha definição racial $(52,6 \%$ - 20), seguido por cães da raça Pit bull (10,5\% - 4), Poodle (7,9\% - 3), Labrador Retriever e Rottweiler (5,2\% 2 de cada); Boxer, Dálmata, Golden Retriever, Lhasa Apso, Shitzu, Teckel e Weimaraner (2,6\% - 1 de cada).

Observou-se que $63,4 \%$ dos cães com DRC apresentavam anemia, sendo estatisticamente significativa $(\mathrm{p}<0,001)$, comparando o grupo controle com os doentes $(\mathrm{p}<0,0001)$, porém não houve diferença entre os grupos doentes ( $p>0,05)$.

$\mathrm{Na}$ avaliação de eletrólitos realizada foi observado um cão com hiponatremia, um com hipocalemia e outro com hipercalemia. Não foi observada diferença significativa na 
avaliação do cálcio ionizado e total, sódio, potássio, cloro e fósforo quanto a todos os grupos $(\mathrm{p}>0,05)$.

$\mathrm{Na}$ análise do efeito linear e quadrático, observou que a creatinina interfere diretamente nos valores de hematócrito, hemoglobina, número de eritrócitos, ureia, densidade urinária, UPC, pressão arterial e albumina $(\mathrm{p}<0,05)$. Já o BNP não influenciou em nenhuma das variáveis analisadas ( $p>0,05)$.

Para classificar a PA dos animais doentes renais e clinicamente saudáveis adotou-se a classificação da IRIS. As médias das triplicatas obtidas foram $<150 /<95$ (2), 150159/95-99 (4), 160-179/100-119 (12), >180/>120 (20). Não foi observada diferença significativa de pressão arterial entre os cães dos distintos grupos $(p>0,05)$.

Quadro 1. Valores de média, desvio padrão e variância das variáveis analisadas e se seguiram a normalidade dos cães com doença renal crônica e clinicamente saudáveis

\begin{tabular}{lcccc}
\hline Variável & Média & Desvio Padrão & Variância & Normalidade \\
\hline Hematócrito & 30.634 & 14.177 & 201.013 & Sim \\
Hemoglobina & 10.153 & 4.794 & 22.987 & Sim \\
Eritrócitos & 4.649 & 2.197 & 4.828 & Sim \\
Leucócitos & 11.546 & 5.038 & 25.387 & Sim \\
Plaquetas & 216 & 129.353 & 16732.45 & Sim \\
Proteína total & 7.910 & 1.484 & 2.203 & Sim \\
Albumina & 2.711 & 0.849 & 0.721 & Não \\
Ureia & 118.335 & 100.740 & 10148.74 & Não \\
Creatinina & 3,421 & 2,579 & 6,654 & Sim \\
Sódio & 147.714 & 7.474 & 55.875 & Sim \\
Potássio & 5.074 & 1.013 & 1.027 & Sim \\
Cálcio Ionizado & 1.349 & 0.232 & 0.053 & Sim \\
Cálcio total & 9.458 & 13.309 & 1.771 & Sim \\
Cloro & 113.584 & 13.342 & 178.025 & Sim \\
Fósforo & 1.316 & 0.637 & 0.406 & Não \\
Densidade urinária & 1016.08 & 6.506 & 42.333 & Não \\
UPC & 1.666 & 1.741 & 3.031 & Não \\
Pressão Arterial & 184.423 & 35.462 & 1257.58 & Sim \\
Onda P & 39.020 & 4.935 & 24.361 & Não \\
Intervalo PR & 107.653 & 23.220 & 539.171 & Não \\
Intervalo QRS & 38.058 & 19.391 & 376.016 & Não \\
Intervalo QT & 146.769 & 29.420 & 865.592 & Não \\
Amplitude QRS & 0.926 & 0.459 & 0.211 & Não \\
Amplitude_T & 0.270 & 0.143 & 0.020 & Não \\
Média BNP & 0.451 & 0.230 & 0.053 & Sim \\
& & & &
\end{tabular}

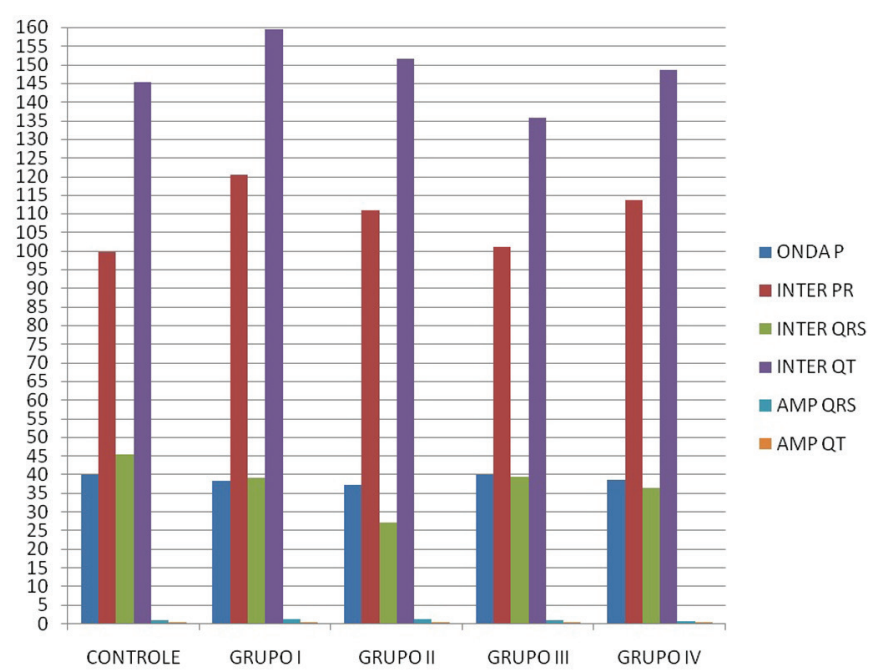

Fig.1. Achados eletrocardiográficos em cães sem alterações clínicas e doentes renais crônicos no estágio I, II, III e IV.

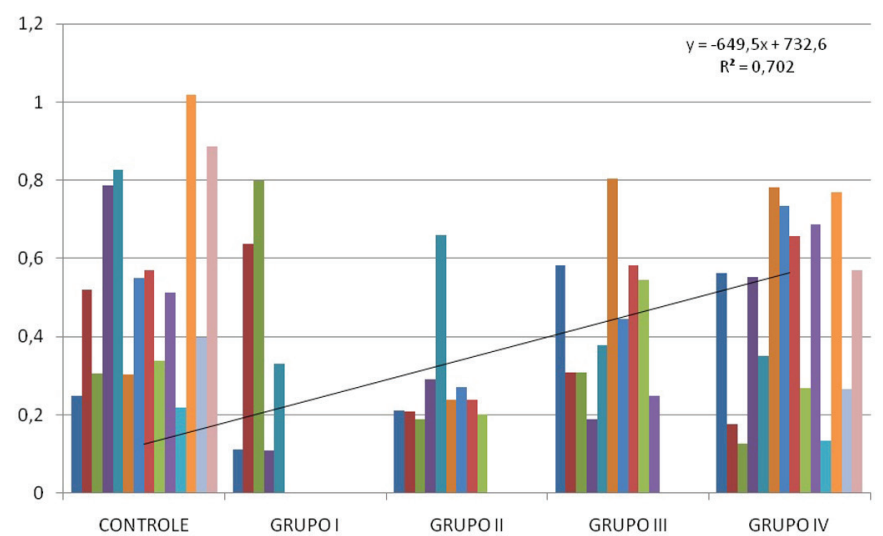

Fig.2. Concentração sérica de peptídeo natriurético B em cães sem alterações clínicas e com doença renal crônica no estágio I, II, III e IV.

Os valores da UPC foram agrupados seguindo a orientação da IRIS, sendo $1(<0,2), 8(0,2-0,5), 29(>0,5)$. A análise mostrou relevância estatística $(\mathrm{p}<0,0001)$ e diferença entre os estágios controle e doentes $(\mathrm{p}<0,05)$. A proteinúria não variou significativamente entre os estágios II, III e IV, sendo que o grupo de cães clinicamente saudáveis se apresentou semelhante ao estágio I ( $\mathrm{p}>0,05)$.

Não foram observados achados significativos $(p>0,05)$ nas avaliações eletrocardiográficas nos distintos grupos (Fig.1). Porém observou-se uma tendência do intervalo QT ser maior nos estágios mais avançados da doença.

Neste estudo, a avaliação do peptídeo natriurético B em cães não teve valores estatisticamente diferentes nos distintos estágios de DRC $(p>0,05)$. Contudo, verifica-se uma tendência de aumento da concentração de BNP nos estágios III e IV da doença renal crônica (Fig.2).

\section{DISCUSSÃO}

0 presente estudo corrobora com outros estudos onde citam que a DRC é mais frequente em cães idosos, porém, pode ocorrer em todas as idades dependendo da etiologia (Mcgrotty 2008, Polzin et al. 2011, Bartges 2012).

Não existe predileção racial para DRC (McGrotty 2008, Polzin et al. 2011). Nesse estudo observou uma maior freqüência em cães sem raça definida devido a maior representatividade destes cães no Hospital Veterinário Universitário onde foi realizado o estudo.

A anemia em cães com doença renal crônica, como observada neste estudo, pode decorrer da incapacidade funcional do rim em produzir eritropoietina. Com a progressão da doença renal, a anemia se agrava. Apesar da redução na produção de eritropoietina ser considerada a causa primária da anemia, outros fatores estão envolvidos como efeito das toxinas urêmicas gerando um menor tempo de sobrevida das hemácias e perda de sangue pelo trato gastrointestinal (Mcgrotty 2008, Polzin et al. 2011, Bartges 2012).

Apesar de ser um critério de inclusão, a azotemia é o principal achado laboratorial presente em animais com doença renal (Polzin et al. 2011, Bartges 2012). No presente estudou se verificou diferença significativa dos achados de 
ureia e creatinina $(p<0,0001)$. Foi constatada diferença entre o grupo controle e os doentes $(p<0,001)$ e entre os estágios dos cães doentes $(\mathrm{p}<0,001)$ sendo que quanto mais grave a doença maior é a azotemia (Finco 2004, Castro et al. 2009, Barrak 2013).

Os rins contribuem para o equilíbrio hídrico e eletrolítico, na DRC é comum encontrar hiperfosfatemia, hipercalcemia ou hipocalcemia (McGrotty 2008, Polzin et al. 2011). Entretanto, neste trabalho não foi observada diferença estatisticamente significativa para a análise de cálcio ionizado e total, sódio, potássio e cloro. Possivelmente esse resultado foi decorrente dos animais que compuseram o estudo apresentarem essa função renal ainda preservada, pois já é comprovado que o hiperparatireoidismo secundário renal pode ocorrer com o avanço da doença pela deficiência em excretar fósforo e reabsorver cálcio (Lunn 2011, Polzin et al. 2011, Bartges 2012).

Embora a hipertensão arterial seja uma das complicações mais comuns da DRC (Polzin et al. 2011, Bartges 2012, Courand \& Lantelme 2014), não foi observada diferença significativa $(p<0,05)$ nos valores de sua mensuração, mesmo esta sendo realizada pelo mesmo avaliador nos cães aparentemente tranquilos e em triplicata. Tal resultado é justificado pelo estresse dos cães em ambiente hospitalar, fato já amplamente difundido em humanos (Singh 2012, Afsar 2013) e comprovado em cães (Brown et al. 2007).

A despeito de não ter sido verificado neste estudo correlação das variáveis com a PAS, em outro estudo Finco (2004) observou correlação de UPC com PAS elevada em cães doentes renais, demonstrando que o cães doentes renais crônicos devem ser monitorados e tratados para minimizar os efeitos da hipertensão aos vários órgãos. Lalor et al. (2009) observou aumento de BNP em gatos hipertensos com DRC ao compará-los com gatos normotensos com DRC.

A permeabilidade seletiva da membrana basal glomerular restringe a filtração da maior parte das proteínas plasmáticas, o que leva à filtração apenas de proteínas com baixo peso molecular e daquelas com carga elétrica neutra ou positiva, porém com perda dos glomérulos na DRC a filtração seletiva não ocorre (Castro et al. 2009, Polzin et al. 2011, Barrak 2013), sendo a creatinina uma avaliação indireta da taxa de filtração glomerular como observado nos cães avaliados com DRC (Polzin et al. 2011). A proteinúria está associada à progressão da DRC em cães e gatos, no entanto, não se verificou tal tendência nos cães doentes renais crônicos.

Estudos em humanos demonstram que a DRC interfere intimamente com a atividade do coração levando a episódio de hipóxia do miocárdio, arritmias e até morte em casos mais graves (Yoda et al. 2012). Neste estudo os resultados não foram estatisticamente significativos ( $p>0,05)$, mas foi observada uma tendência do intervalo QT ser maior com o avanço da doença, fato que pode estar associado com remodelamento cardíaco levando hipertrofia ventricular, que pode ocorrer antes mesmo do aparecimento da alteração cardíaca propriamente dita (Lalor et al. 2009).

O BNP é um biomarcador avaliado na detecção de doen- ça cardíaca e avaliação da gravidade da insuficiência cardíaca congestiva em cães e gatos (Connolly et al. 2008, Lalor et al. 2009, Cavalcante et al. 2013). Assim como em gatos, não foi observado correlação do BNP nos distintos estágios da DRC em cães ao compará-los com cães saudáveis (Lalor et al. 2009).

\section{CONCLUSÕES}

A aferição do BNP em cães em distintos estágios da DRC não se mostrou eficiente, por não interferir em nenhuma das variáveis avaliadas nesse estudo.

Embora a literatura cite que a DRC possa causar hiperparatireoidismo secundário renal, não foram observados alterações significativas nos valores de cálcio ionizado e total, sódio, potássio e cloro.

Também não foi observada influência da DRC nas ondas eletrocardiográficas, entretanto, a tendência do aumento da amplitude QT sugere doença renal mais avançada.

A anemia é uma grande conseqüência da doença renal crônica, sendo assim o clínico deve estar atendo a necessidade de transfusão sanguínea e reposição de hormonal para melhorar a qualidade de vida dos pacientes.

\section{REFERÊNCIAS}

Afsar B. 2013. Comparison of demographic, clinical, laboratory parameters between patients with sustained normotension, white coat hypertension, masked hypertension, and sustained hypertension. J. Cardiol. 61:222-226.

Barrak M.P. 2013. Clinical approach to advanced renal function testing in dogs and cats. Vet. Clin. N. Am., Small Anim. Pract. 43:1193-1208.

Bartges J.W. 2012. Chronic kidney disease in dogs and cats. Vet. Clin. N. Am., Small Anim. Pract. 42:669-692.

Brown S., Atkins C., R. Bagle R., Carr A., Cowgill L., Davidson M., Egner B., Elliott J., Henik R., Labato M., Littman M., Polzin D., Ross L., Snyder P. \& Stepien R. 2007. Guidelines for the identification, evaluation, and management of systemic hypertension in dogs and cats. J. Vet. Intern. Med. 21:542-558.

Castro M.C.N., Marcello G.C.G., Alencar N.X. \& Ferreira A.M.R. 2009. Avaliação da relação proteína-creatinina urinária em gatos com doença renal crônica. Pesq. Vet. Bras. 29:605-609.

Cavalcante C.Z., Kogika M.M., Bacic A. \& Santoro M.L. 2013. Avaliação da albuminúria e da eletroforese de proteínas urinárias de cães com hiperadrenocorticismo e a relação com a pressão arterial sistêmica. Pesq. Vet. Bras. 33(11):1364-1370.

Connolly D.J., Magalhaes R.J., Syme H.M., Boswood A., Fuentes V.L., Chu L. \& Metcalf M. 2008. Circulating natriuretic peptides in cats with heart disease. J. Vet. Intern. Med. 22:96-105.

Courand P. \& Lantelme P. 2014. Significance, prognostic value and management of heart rate in hypertension. Arch. Cardiovasc. Dis. 107:4857.

Essner A., Sjöströmc R., Ahlgren E., Gustås P., Edge-Hughes L., Zetterberg L. \& Hellström K. 2015. Comparison of Polar ${ }^{\circledR}$ RS800CX heart rate monitor and electrocardiogram for measuring inter-beat intervals in healthy dogs. Physiol. Behav. 138:247-253.

Finco D.R. 2004. Association of systemic hypertension with renal injury in dogs with induced renal failure. J. Vet. Intern. Med. 18:289-294.

Garcia-Navarro C.E.K. 1996. Manual de Urinálise Veterinária. Livraria Varela, São Paulo.

Jain N.C. 1993. Essentials of Veterinary Hematology. Lea and Febiger, Philadelphia.

Kaneko J.J., Harvey J.W. \& Bruss M.L. 1997. Clinical Biochemistry of Domestic Animals. Elsevier. 
Lalor S.M., Connolly D.J., Elliott J. \& Syme H.M. 2009. Plasma concentrations of natriuretic peptides in normal cats and normotensive and hypertensive cats with chronic kidney disease. J. Vet. Cardiol. 11:S71-S79.

Lunn K.F. 2011. The kidney in critically ill small animals. Vet. Clin. N. Am., Small Anim. Pract. 41:727-744.

Mcgrotty Y. 2008. Diagnosis and management of chronic kidney disease in dogs and cats. Comp. Anim. Pract. 30:502-507.

Meurs K.M., Miller M.W. \& Slater M.R. 2000. Arterial blood pressure measurement in a population of healthy geriatric dogs. J. Am. Anim. Hosp. Assoc. 36:497-500.

Moesgaard S.G., Falk T., Teerlink T., Guðmundsdóttir H.H., Sigurðardóttir S.,
Rasmussen C.E. \& Olsen L.H. 2011. Brain-natriuretic peptide and cyclic guanosine monophosphate as biomarkers of myxomatous mitral valve disease in dogs. Vet. J. 189:349-352.

Polzin D.J. 2011. Chronic kidney disease in small animals. Vet. Clin. N. Am., Small Anim. Pract. 41:15-30.

Singh S. 2012. Etiology and management of hypertension in chronic kidney disease. Clin. Quer., Nephr. 1:259- 267.

Yoda S., Nakanishi K., Tano A., Kasamaki Y., Kunimoto S., Matsumoto N., Sato Y. \& Hirayama A. 2012. Stratification of cardiovascular events in patients at all stages of chronic kidney disease using myocardial perfusion SPECT. J. Cardiol. 60:377-382. 